\title{
AS FUNÇÕES DA RAZÃO NO DE OFFICIIS DE M. T. CICERO
}

THE FUNCTIONS OF THE REASON OF OFFICIIS OF M. T. CICERO

Bruno D'Ambros ${ }^{*}$

\section{RESUMO}

Pretendemos extrair uma compreensão geral do significado do termo ratio na obra De officiis de M. T. Cícero e, por extensão em sua obra política em geral, a fim de termos uma noção menos estreita do que Cícero compreendia sobre a ratio e, consequentemente, sobre o significado da própria razão, sua função e sua utilidade para o bem da conduta moral individual e para o bem da re publica.

PALAVRAS-CHAVE: Razão. De officiis. Cícero. Filosofia romana.

\section{ABSTRACT}

We intend to extract a general understanding of the meaning of the latin term ratio into the $\mathrm{M}$. T. Cicero's De officiis and, by extension, in his political work in general, in order to have a less narrow notion than Cicero understood about the ratio and consequently about the meaning of reason itself, its function and its usefulness for the sake of individual moral conduct and for the good of the public.

KEYWORDS: Reason. De officiis. Cicero. Roman philosophy.

\section{Introdução}

O termo latino ratio - e todas as suas declinações (nom: ratio, rationes; gen: rationis, rationum; dat: rationi, rationibus; acc: rationem, rationes; abl: ratione, rationibus; voc: ratio, rationes $)^{1}$ - aparece em toda a obra De Officis de M. T. Cicero exatamente 83 vezes nos três livros da obra (48, 23 e 12 vezes, respectivamente), ${ }^{2}$ o que nos leva a considerar seriamente sua ocorrência dentro dessa obra clássica em filosofia política.

As duas traduções que utilizamos neste artigo, a já consagrada em inglês do classicista Walter Miller e a em português de Angélica Chiappetta, traduzem essas 83 ocorrências do termo na obra de maneiras diversas. Por exemplo, a de Miller traduz o termo 29 vezes por reason, 7 por rational, 4 por relation, 3 por question, mean, way, 2 por wisdom, classification, argument, method, principles, system, process of reasoning, rule etc. A de Chiappetta, por sua

\footnotetext{
* Doutorando em Filosofia pela Universidade Federal do Paraná. Mestrado em Filosofia pela Universidade Federal de Pelotas. Membro dos grupos de pesquisa CNPQ "Razão prática e moral” (UFPEL) e "Ética, filosofia jurídica e política" (UEL). Membro do corpo editorial da Revista Seara Filosófica (UFPEL). Email: dambrosbruno@gmail.com.

${ }_{1}^{1}$ Porém nunca no vocativo ou no genitivo plural.

2 Os trechos do De officiis onde o termo em questão aparece são: I, 7, 8, 9, 10, 11, 12, 14, 16, 20, 43, 50, 53, 57, $67,76,79,80,83,90,92,94,95,99,101,102,107,120,121,126,130,132,135,136,139,141,148 ;$ II, 6, 7, 9, 11, 13, 18, 19, 21, 39, 42, 46, 48, 49, 52, 53, 60, 64, 83, 84; III, 20, 23, 28, 52, 55, 63, 68, 84, 104, 118.
} 
vez, traduz 40 vezes por razão, 3 por método, modo e regra, 2 por meio, princípio e plano e o restante 1 vez por esfera, cálculo, custo, caso, raciocínio, peso, determinação, decisão, conta, proporção, opinião, motivo, ponto de vista, estado e argumento. Essa contagem nos mostra algumas peculiaridades nas respectivas traduções, no entanto não usaremos todas as acepções do termo, mas somente aquelas em que ratio é traduzida como, de fato, razão, pois são esses trechos que nos mostrarão a compreensão ciceroniana do termo e todas as suas funções.

Pretendemos extrair uma compreensão geral do significado do termo em questão nessa obra específica e, por extensão na obra política de Cícero em geral. Cremos que através deste trabalho podemos ainda ter uma noção menos estreita do que Cícero compreendia sobre a ratio, sobre seu significado, sua função e sua utilidade nos vários processos do pensamento moral e ético. Comumente alhures se acusa Cícero de, ao traduzir para o latim o termo grego logos, ter incorrido numa redução e o interpretado como mero cálculo utilitário. No entanto não pensamos assim e gostaríamos de mostrar isso através da ocorrência de passagens seminais sobre o termo ratio em seu último e mais importante texto, o De officiis.

\title{
As funções da ratio
}

Vamos começar pela definição do Oxford latin dictionary, de Glare, apresentada para o termo ratio:

\begin{abstract}
1.The act of reckoning, calculation, to make a calculation, keep count, a record os numbers, register; 2. A financial reckoning, the calculation of accounts or the figures obtained from this, money, standing to one's account, credit, balance, an official account, a clerk of accounts, the accounts balance, a satisfactory account can be given, to square one's account; 3. A proportion, relation, in proportion, proportionately; 4 . The act or process of reasoning or working out, reckoning, theory; 5. An explanation, reason, ground, a reason for, the act of showing a sufficient reason for one's conduct, justification, that which accounts, explanation; 6. A descriptive account; 7. The exercise of reason, the faculty of reason, with good reason, sensibly, that which is reasonable, good sense; 8 . The action of concerning oneself with or taking account of, consideration of, to take account of, pay regard to, to take official account of a candidate for office; 9. An affair, concern, business; 10 . A plan of action, policy, scheme, to embark on a scheme, the purpose; 11. A guiding principle, system, rule, defining the field covered, a principle of society, social doctrine, a principle inculcated by nature, common sense, the popular cause; 12 . The ruling principle of natural forces etc., law of nature, characteristic action or behavior of things, property, genius, constitution; 13. Principle or manner os construction, structure, pattern, the pattern of events, a plan or pattern of life, procedure, according to rule, properly; 14. A manner, method, means, a way of doing, a contrivance, device; 15 . A quality, kind.
\end{abstract}

Acima nos são dadas quinze definições de ratio: avaliação, cálculo, proporção, teoria, explicação, fundamento, plano, propósito, sistema, regra, princípio, senso comum, padrão, método, meio etc. Essas definições são bem diversas e, no entanto, estão presentes nos textos 
latinos que usam o termo.

Começamos, assim, vendo o que o próprio Cícero nos diz sobre o termo ratio na primeira e mais importante passagem sobre o termo em De officiis I, 11:

O homem, por outro lado, sendo partícipe da razão e por ela discernindo as consequências, vê as causas e não ignora os progressos e os antecedentes; compara semelhanças, liga-as, une as coisas futuras às presentes, percebe facilmente o curso da vida e prepara o necessário para passá-la.

Nesse trecho Cícero elenca sete atividades da ratio e através delas podemos extrair uma noção genérica de sua compreensão do termo: 1) discernir consequências (consequentia cernit), 2) ver as causas das coisas (causas rerum videt), 3) conhecer o progresso e o antecedente (praegressus et quasi antecessessiones non ignorat), 4) comparar as semelhanças (similitudines comparat), 5) ligar coisas presentes às futuras (rebusque praesentibus adiungitatque annectit futuras), 6) perceber o curso da vida (facile totius vitae cursum videt ad), 7) preparar as coisas necessárias (degendam praeparat res necessarias).

Se atentarmos para as seis primeiras atividades, todos os verbos usados são atividades intelectuais, como discernir, ver, conhecer, comparar, ligar, perceber e preparar. Assim, de modo genérico, esse trecho mostra o aspecto primordial e mais óbvio da razão, ou seja, sua função intelectual. As três primeiras atividades são funções intelectuais de causalidade, as três seguintes atividades são funções intelectuais de analogia e a última não parece falar sobre uma função intelectual, mas uma função econômica da razão.

Comecemos pelas três primeiras atividades que mostram uma função intelectual de causalidade: discernir as consequências, ver as causas e conhecer o progresso e o antecedente. O verbo cerno significa discernir, distinguir, compreender, reconhecer, separar, dividir, deliberar; claramente acepções intelectuais. No direito romano o verbo cerno significa declarar a aceitação de uma hereditariedade, ou seja, uma sucessão ininterrupta no tempo entre um antepassado e sua ligação com alguém no futuro. A segunda atividade é ligada à primeira, pois para se verem as causas das coisas é preciso ter antes discernido suas consequências. Parece que na compreensão de Cícero, o ato de discernir as consequências vem antes daquele de ver as causas. A terceira atividade é conhecer o progresso e o antecedente. Na tradução de Miller temos "understands the relation of cause to effect and of effect to cause." Essas são as três primeiras atividades que mostram uma função intelectual de causalidade da razão, ou seja, a primeira função intelectual da razão é compreender a relação causal entre as coisas, as ações e as ideias.

As três outras atividades mostram a função intelectual de analogia da razão. Ou seja, o 
segundo papel da razão é criar analogias entre as coisas, ações e ideias: comparar as semelhanças, ligar coisas presentes às futuras, perceber o curso da vida. Precisamente Miller traduz o termo similitudines comparat por “draw analogies”. Não basta compreender relações de causalidade, é necessário ligar as várias coisas, ações e ideias umas com as outras para compará-las.

Por fim, a última atividade da razão não parece ser uma função intelectual, mas sim uma função prática da razão, que aqui chamo de função econômica da razão. Esta é, então, a segunda função da ratio, uma função econômica, que é preparar as coisas necessárias (degendam praeparat res necessarias). A razão assim tem uma utilidade prática, que seria, através de sua função intelectual de causalidade e analogia, preparar as coisas necessárias para a vida, desde as provisões materiais até as morais (para Cícero não há separação entre uma e outra: ser moralmente bom implica em ser minimamente precavido materialmente, sendo este um sinal daquele). Um homem racional seria aquele que usa a razão para se prevenir para as necessidades futuras da vida, doutro modo a razão seria inútil. Assim o comportamento econômico (pensar nos reveses do futuro e precaver-se deles é um comportamento racional.) A negligência para com o corpo é condenada alhures em De officiis, não porque mostra um desprezo arrogante pelo afã material da sociedade, mas porque mostra um desprezo para com a própria vida, corpo, saúde e bem-estar. Isso é irracional para Cícero. Devemos atentar para algo muito peculiar nesse trecho. Todas as sete atividades da razão elencadas tem a ver com o futuro, desde as atividades estritamente intelectuais, (causalidade e analogia) até esta última, econômica.

O segundo trecho importante onde Cícero apresenta mais uma função da razão está em I,50 onde elencam-se mais algumas atividades da ratio (juntamente com a oratio): ensinar (docendo), aprender (discendo), comunicar (communicando), discutir (disceptando), julgar (iudicando). Esta é a função comunicativa da razão. As atividades listadas acima são todas atividades essencialmente orais e estão intrinsecamente ligadas à primeira função, pois o intelecto precisa se comunicar e para isso utiliza a fala, naturalmente. A atividade de julgar (iudicando) não é, contrariamente ao uso do termo pela filosofia moderna, uma atividade intelectual, mas oral, como a etimologia do próprio termo latino demonstra. O julgamento, no contexto jurídico romano, sempre é proferido por alguém e, portanto, uma ação oral e não intelectual.

Em I,12 onde se diz que uma das funções da ratio é "conciliar o homem com o homem". É a mesma função que aparece em II, 11 onde se diz que "os homens é que são mais 
úteis aos homens." Assim uma das funções da ratio é a sua utilidade social, ou função social da razão.

Em I,14 nos diz que, a ratio possibilita ao homem sentir (sentire) a ordem (ordo), a conveniência (deceat) e a medida das ações e palavras (factis dictisque). A ratio é o que permite ao homem "que não se faça nada indecorosa e efeminadamente e, enfim, para que em todas as ações e opiniões coisa alguma se faça ou pense de libidinoso." Igualmente em I, 130 se diz para cultivar "uma higiene sem exageros ou requinte, suficiente apenas para evitar uma negligência muito tosca e pouco civilizada. A mesma regra (ratio) se aplica ao vestuário, no qual, como em tudo, o meio-termo é o melhor.” Emerge outra função da razão aqui, a daquele fator que possibilita ao homem agir de modo belo e gracioso, o que poderíamos chamar de função estética da razão.

Em I,79 afirma-se que o corpo deve obedecer à ratio e isso é possível através de exercícios físicos. O mesmo preceito de "tornar o desejo obediente à razão" aparece em I, 132 e em I,41 e em II,18, onde se diz que a razão deve "coibir os movimentos desordenados da alma" (pathé) e os "apetites" (hormai), docilizando-os. Igualmente, em I, 101 fala-se em duas forças das almas, o apetite (appetitu) e a razão (ratio), cuja função é "apontar e esclarecer o que deve ser feito e o que deve ser evitado" e que "portanto, a razão manda e o apetite obedece (ratio praesit appetitus obtemperet)." Igualmente o mesmo percebe-se em I, 90 onde se vê que, na ausência da ratio, há a autoconfiança excessiva, a irrefreabilidade e a indomesticabilidade e, assim, portanto, por inversão, outras funções da ratio aparecem no texto, como refrear e domesticar a autoconfiança "a fim de descobrir a fragilidade das coisas humanas e a inconstância da Fortuna." A razão tem a função, portanto, de prudência nas ações. Encontramos aqui a função domesticadora da razão.

Em I,83 revela-se, quase sem querer, uma diferenciação recorrente dos providos de ratio dos desprovidos, a saber, a calma e a ira, respectivamente. A calma e o desejo por ela são característicos da ratio; e a ira é frequentemente ligada à irracionalidade e loucura, como se atestam em vários outros textos latinos, como as Cartas de Sêneca e sua peça Heracles furens, título traduzido frequentemente tanto por Hércules furioso quanto por A loucura de Hércules. $\mathrm{Na}$ psicologia estoica, da qual Cícero partilha, a fúria - ou ira - é própria dos loucos ou irracionais. Igualmente em I, 102 a mesma oposição ciceroniana entre razão/calma e não razão/ira aparece. Quando os apetites se curvam à razão eles se tornam serenos e livres de tribulações, em suma, calmos, constantes e moderados. No entanto, quando não o fazem eles "se encolerizam, alimentam paixões ou medos, entregam-se aos extremos da volúpia" e então 
há sinais físicos visíveis e facilmente discerníveis, como transtornos na "físionomia, voz, gestos e atitudes." Em II, 46 diz-se que os trabalhos do espírito, do engenho e da razão são maiores que a força, o que sugere que a razão é contrária à força bruta dos momentos de ira. Assim, portanto, emerge mais uma função da ratio, a saber, a de calmante para as tribulações psíquicas ou função terapêutica da razão.

Em III, 68 vemos mais uma função da "razão e inteligência", a saber, de coibição das astúcias, que é mais eficaz que a "mão forte da lei." Ao contrário da concepção nietzschiana de "razão", que a interpretava justamente como um cálculo astucioso somente, a concepção ciceroniana é completamente oposta a qualquer tipo de astúcia. Os homens, em sua ação cotidiana, se veem por vezes impelidos a usar da astúcia. Tanto na política quanto na economia, nos interesses públicos ou privados, a astúcia é a má utilização da razão. Um método de coibição é a lei, porém ineficaz. Mesmo com todas as sanções e ameaças da lei contra o uso da astúcia e má-fé, ainda assim o homem se utiliza desse recurso para levar vantagens. Cícero, ao prescrever a razão como método eficaz de coibição da astúcia, está contrapondo a razão à astúcia, mostrando assim que a razão não tem nada a ver com a astúcia, contrariando, portanto, aqueles que interpretam a astúcia e esperteza como inteligência ou racionalidade. A astúcia, ao contrário, não faz parte da razão porque se guia meramente por cálculos utilitários e pragmáticos, e a razão está distante de ser meramente utilitária ou pragmática. Aspectos de pragmatismo e utilitarismo se encontram no funcionamento da razão, mas não são integrais. No mesmo trecho Cícero diz que "a razão, em consequência, exige que nada façamos astuciosamente, nada fingidamente, nada falaciosamente.” Em suma, aquilo que é comum na mentalidade de muitas pessoas, de que a astúcia, a dissimulação e a trapaça são sinônimos de ser inteligente ou racional, está errado. A razão se opõe a tais comportamentos mentais. Assim, outra função da razão que aparece em De officiis é a função veridictiva: a razão deve sempre dizer a verdade e levar a agir conforme a verdade.

\section{Conclusão}

Finalmente, em III, 23 fala-se sobre uma razão natural que é a lei divina e humana. Em toda a obra ciceroniana há a pressuposição da existência de uma razão natural e de uma lei natural. Ou seja, da conformidade com a lei natural extrair-se-ia uma razão natural: o homem está em conformidade com a natureza quando exerce sua razão, porque a própria natureza é racional. Portanto, o critério da razão não é interno, mas externo. Sua fonte está fora do próprio sujeito cognoscente, a natureza. O homem é naturalmente racional porque a natureza é 
racional e, o homem, como parte da natureza, também é racional. Sua racionalidade não decorre de sua vontade própria em ser racional, mas do próprio fato de se ser humano e, involuntariamente, ou naturalmente, racional. A naturalidade aqui significa precisamente involuntariedade. A racionalidade não se conquista, mas se ganha. Mas, perguntar-se-ia, como tantas pessoas são irracionais então, mesmo possuindo naturalmente a razão? Porque elas desviaram-se de sua verdadeira natureza racional e decaíram em processos cognitivos errôneos e não naturais, artificiais, forçando a razão para elucubrações erradas por perguntas erradas que se fazem, e caindo em respostas erradas.

Todas as funções da razão acima apresentadas extraídas do De officiis - intelectual, econômica, comunicativa, social, domesticadora, terapêutica, veridictiva - se fundam nesta pressuposição da existência de uma razão natural. Assim Cícero naturaliza a razão e suas funções são somente decorrência daquilo que é natural no homem: a intelectualidade, o comportamento econômico, a comunicação, a sociabilidade, a domesticabilidade, a temperança e a honestidade e transparência das intenções e ações. Desse modo todas as críticas contemporâneas feitas à racionalidade - a crítica de Marx, Nietzsche, Freud, Weber, Wittgenstein, Horkheimer, Foucault et al. - vão contra a tradição clássica, fundada por Cícero, sobre o que é a razão e quais as suas funções.

Por exemplo, em uma chave marxista a razão é sempre razão de uma classe específica; numa chave nietzschiana a razão é astuta contenção da vontade de potência; numa chave freudiana a razão estaria a serviço da regulação dos desejos; numa chave weberiana a razão gera desencantamento do mundo; numa chave wittgensteiniana a razão não teria nada a dizer sobre ética e moral, limitando-se a dizer coisas somente sobre ciência, técnica e lógica; numa chave horkheimiana a razão é eclipsada por sua instrumentalidade técnica; numa chave foucaultiana a razão é instrumento de poder e dominação. Em suma, a filosofia contemporânea parece ter criado uma desconfiança sobre a possibilidade de uma razão natural, universal, objetiva e sobre as funções clássicas da razão, como apresentadas no De officiis. Ao criar esta desconfiança, esses autores não puseram nada no lugar, restando apenas a dúvida para com nossa capacidade de alcançar alguma verdade. No entanto o mesmo cinzel usado para construir a estátua do antigo deus, foi usado por esses críticos para demoli-lo: o cinzel da própria razão.

\section{REFERÊNCIAS}

CICERO, Marcus Tullius. De Officiis. Tradução de Walter Miller. Loeb Classical Library 
XXI. Harvard University Press: Cambridge/Massachusetts, 1913/2005.

CÍCERO, Marco Túlio. Dos deveres. Tradução de Angélica Chiappetta. Martins Fontes: São Paulo, 1999.

ERNOUT, Alfred; MEILLET, Antoine. Dictionnaire étymologique de la langue latine: histoire des mots. 4. ed. Paris: Klincksieck, 2001.

GLARE, P. G. W. Oxford Latin Dictionary. Clarendon Press: Oxford, 1982.

LIDDEL, Henry George \& SCOTT, Robert. A greek-english lexicon. Revisado e aumentado por Sir Henry Stuart Jones e Roderick McKenzie. Clarendon Press: Oxford, 1996. 